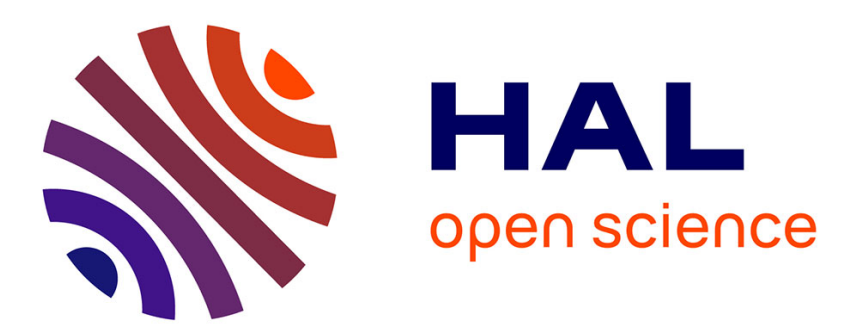

\title{
Novel half-bridge inductive DC-DC isolated converters for fuel cell applications
}

Yves Lembeye, Viet Dang Bang, Guillaume Lefèvre, Jean-Paul Ferrieux

\section{To cite this version:}

Yves Lembeye, Viet Dang Bang, Guillaume Lefèvre, Jean-Paul Ferrieux. Novel half-bridge inductive DC-DC isolated converters for fuel cell applications. IEEE Transactions on Energy Conversion, 2009, 24 (1), pp.203-210. hal-00374401

\section{HAL Id: hal-00374401 https://hal.science/hal-00374401}

Submitted on 8 Apr 2009

HAL is a multi-disciplinary open access archive for the deposit and dissemination of scientific research documents, whether they are published or not. The documents may come from teaching and research institutions in France or abroad, or from public or private research centers.
L'archive ouverte pluridisciplinaire HAL, est destinée au dépôt et à la diffusion de documents scientifiques de niveau recherche, publiés ou non, émanant des établissements d'enseignement et de recherche français ou étrangers, des laboratoires publics ou privés. 


\title{
Novel Half-Bridge Inductive DC-DC Isolated Converters for Fuel Cell Applications
}

\author{
Yves Lembeye, Viet Dang Bang, Guillaume Lefèvre, and Jean-Paul Ferrieux
}

\begin{abstract}
This paper proposes a new class of converters based on the inductive input converters for the design of a power electronic interface for fuel cell (FC) applications. After studying the half-bridge structure, two soft-switching dc-dc converters are analyzed: one operating in zero-voltage-switching (ZVS) mode and the other in zero-current-switching (ZCS) mode. The ZVS converter can overcome the drawbacks of the original structure but is more complicated. The ZCS converter cannot operate at duty cycles below 0.5 , but is simpler and more suitable for FC applications. Flexible choice of components, low losses, high efficiency, and modular converter possibility are all interesting characteristics of these converters. Their operation principle and characteristics are presented in this paper. Experimental results on $2 \mathrm{~kW}$ converters of each structure validate the theoretical analysis.
\end{abstract}

Index Terms-Fuel cell (FC), isolated dc-dc converter, low losses, zero current switching (ZCS), zero voltage switching (ZVS).

\section{INTRODUCTION}

$\mathbf{T}$ HE FUEL CELL (FC) is nowadays well known as an effective generator using hydrogen that is considered as an interesting energy source for the future. An FC produces continuous energy at the output. However, its output characteristics are not linear and depend on the operating point. It is thus necessary to introduce a power electronics interface between this type of generator and the load, so as to stabilize the power supply and improve its efficiency [1], [2]. To ensure the operation in steady state, the interface is composed of a dc-dc converter followed by a dc-ac inverter (Fig. 1). This paper will discuss new dc-dc converters based on the half-bridge inductive converter dedicated to this interface. First, the basic topology is analyzed to introduce the two proposed soft-switching structures: the first one operating in zero-voltage-switching (ZVS) mode and the second in zero-current-switching (ZCS) mode. Both structures exhibit some advantages. The complete description of operation of each converter, as well as its operating condition limits, is presented. This study highlights their advantages and drawbacks. Two prototypes of these two structures validate this theoretical study.

Manuscript received September 27, 2007; revised July 7, 2008. First published January 19, 2009; current version published February 19, 2009. Paper no. TEC-00350-2007.

Y. Lembeye and J.-P. Ferrieux are with Grenoble Electrical Engineering Laboratory (G2Elab), Institut Universitaire de Technologie 1 de Grenoble, Université Joseph Fourier, 38041 Grenoble, France (e-mail: jean-paul.ferrieux@ g2elab.inpg.fr).

G. Lefèvre is with CEFEM Technologies, 07200 Saint Michel de Boulogne, France.

V. D. Bang is with Vietnam Electricity, 10000 Hanoi, Vietnam.

Color versions of one or more of the figures in this paper are available online at http://ieeexplore.ieee.org.

Digital Object Identifier 10.1109/TEC.2008.2006553

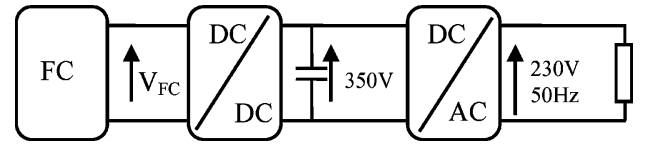

Fig. 1. Basic structure

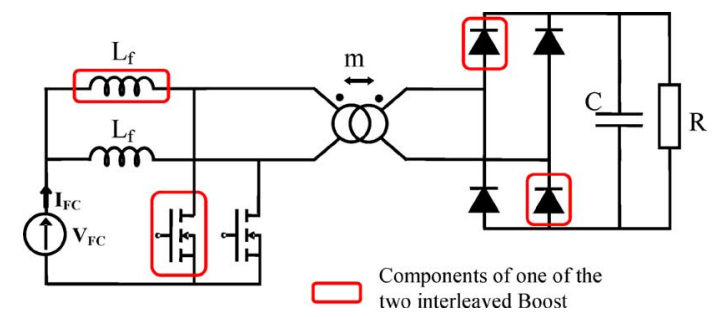

Fig. 2. Half-bridge dc-dc converter

\section{HALF-BRIDGe INDUCTIVE DC-DC CONVERTER}

The basic half-bridge inductive dc-dc converter (Fig. 2) is obtained from an interleaved boost converter by introducing a transformer and a diode bridge at its output. It indicates many interesting characteristics regarding the constraints imposed by the FC [3]. In fact, the inductive nature and the interleaved technique help to achieve low current ripple with small inductors. The transformer facilitates the boost function and optimizes the choice of switches on the primary side. However, the duty cycle must be greater than 0.5 (as explained in the following section). The leakage inductor of the transformer constitutes the main drawback of this structure. The two proposed structures account for this problem.

The main advantage of the chosen structure concerns the possibility of obtaining high voltage ratio by using not only the boost behavior (gain $\propto 1 /(1-\alpha$ ), where $\alpha$ is the duty cycle), but also the high-frequency transformer ratio $($ gain $\propto m$ ). It should be noticed that input current ripple $(\Delta I \propto 2 \alpha-1)$ becomes zero for a duty cycle $\alpha=0.5$.

\section{A. Operation}

Here, we briefly give some elements necessary for the good understanding of the steady-state operation as well as the limits of this converter. To this end, inductors are replaced by current sources and capacitors by voltage sources. The various topologies and the corresponding waveforms are described in Fig. 3.

The MOSFET $\left(V_{\mathrm{MOS1}}, I_{\mathrm{MOS} 1}\right)$, input inductance $\left(I_{L 1}\right)$, and FC $\left(I_{\mathrm{FC}}\right)$ voltage and current waveforms are represented in Fig. 4.

This structure does not function well for $\alpha \leq 0.5$. Indeed, during the phases where $t \in[\alpha T-T / 2, T / 2]$ as well as $t \in$ 


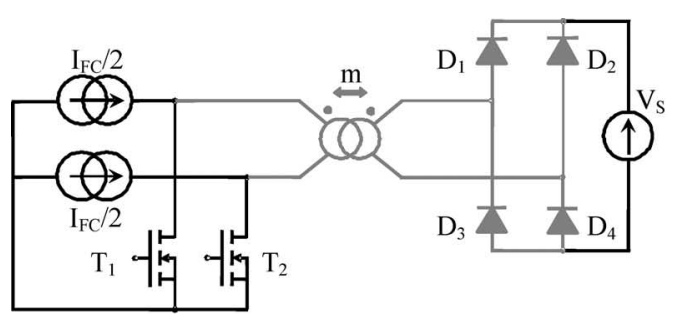

Phase 1

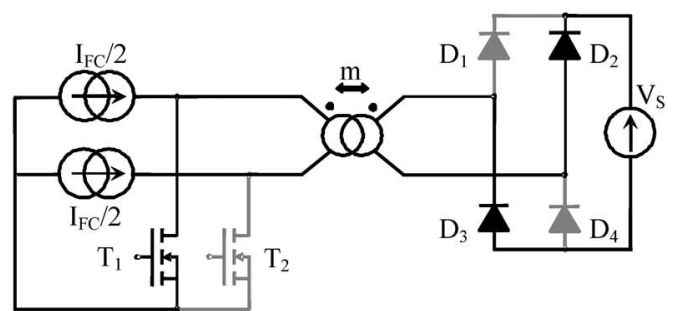

Phase 2

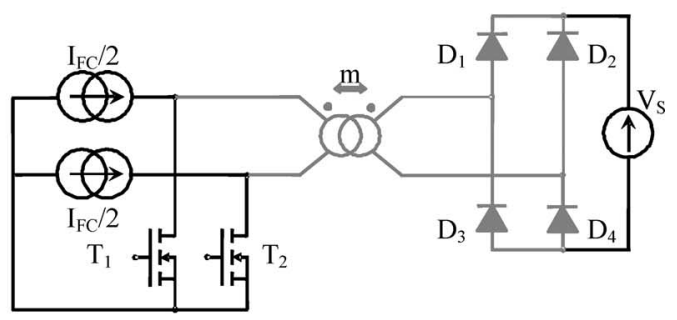

Phase 3

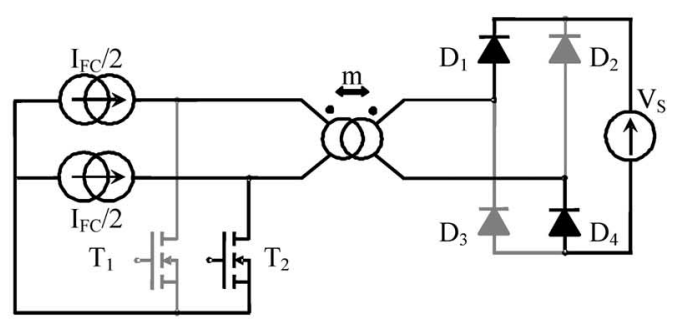

Phase 4

Fig. 3. Operating phases over a switching period. Phase $1: t \in[0,(\alpha-$ $1 / 2) T] T_{1}, T_{2}$ switches are on; phase $2: t \in[(\alpha-1 / 2) T, T / 2] T_{1}$ is ON, $T_{2}$ is OFF; phase $3: t \in[T / 2, \alpha T] T_{1}, T_{2}$ switches are on; phase $4: t \in[\alpha T, T] T_{1}$ is $\mathrm{OFF}, T_{2}$ is ON.

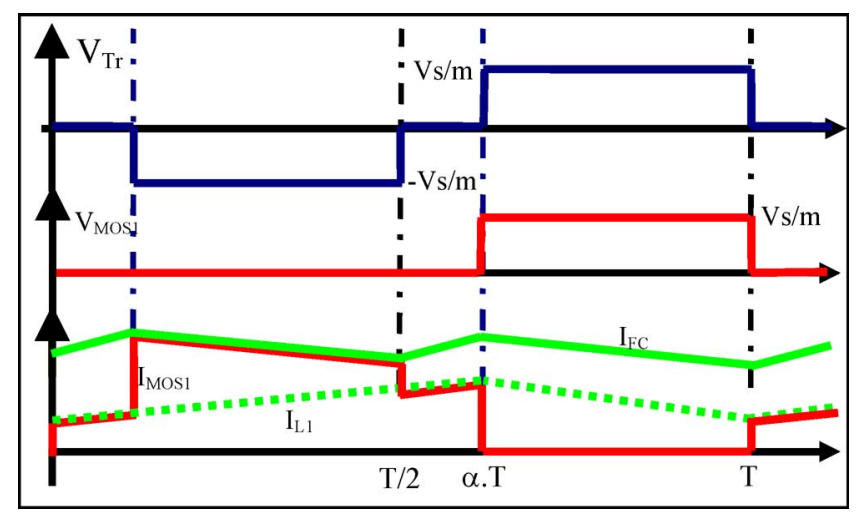

Fig. 4. Main waveforms over a switching period.
TABLE I

CONSTRAINTS ON SEMICONDUCTORS

\begin{tabular}{|l|l|}
\hline \multicolumn{2}{|c|}{ MOSFETs } \\
\hline Maximum current & $\mathrm{I}_{\mathrm{T} \max }=\frac{\mathrm{m} \cdot \mathrm{I}_{\mathrm{S}}}{1-\alpha}+(2 \alpha-1) \frac{\mathrm{V}_{\mathrm{FC}}}{2 . \mathrm{L}_{1} \cdot \mathrm{F}}$ \\
\hline Average current & $\mathrm{I}_{\mathrm{Tav}}=\frac{\mathrm{m} \cdot \mathrm{I}_{\mathrm{S}}}{2 .(1-\alpha)}$ \\
\hline RMS current & $\mathrm{I}_{\text {Trms }}=\frac{\mathrm{m} \cdot \mathrm{I}_{\mathrm{S}}}{2 .(1-\alpha)} \sqrt{3-2 . \alpha}$ \\
\hline Maximum voltage & $\mathrm{V}_{\text {T max }}=\frac{\mathrm{V}_{\mathrm{S}}}{\mathrm{m}}$ \\
\hline \multicolumn{2}{|c|}{ Output rectifier diodes } \\
\hline Maximum current & $\mathrm{I}_{\mathrm{D} \max }=\frac{\mathrm{I}_{\mathrm{S}}}{1-\alpha}+(1-\alpha) \frac{\mathrm{V}_{\mathrm{FC}}}{2 \cdot \mathrm{m} \cdot \mathrm{L}_{1} \cdot \mathrm{F}}$ \\
\hline Average current & $\mathrm{I}_{\mathrm{Dav}}=\frac{\mathrm{I}_{\mathrm{S}}}{2}$ \\
\hline RMS current & $\mathrm{I}_{\text {Drms }}=\frac{\mathrm{m} \cdot \mathrm{I}_{\mathrm{S}}}{2 . \sqrt{1-\alpha}}$ \\
\hline Maximum voltage & $\mathrm{V}_{\mathrm{D} \max }=\mathrm{V}_{\mathrm{S}}$ \\
\hline
\end{tabular}

$[\alpha T, T]$, the topology of the circuit requires that the input inductors should be in series, which is strictly forbidden. As a consequence, the duty cycle will be chosen greater than 0.5 in order to avoid this problem.

\section{B. Characteristics and Constraints}

The output voltage expression in continuous conduction mode should be estimated by using the average voltage on the MOSFET switches

$$
V_{\mathrm{MOS} 1-\mathrm{AV}}=(1-\alpha) \frac{V_{S}}{m}=V_{\mathrm{FC}} \Rightarrow V_{S}=m \frac{V_{\mathrm{FC}}}{1-\alpha} .
$$

The input current ripple is reduced with regard to the ripples of each inductor; it will be null for $\alpha=0.5$

$$
I_{\mathrm{FC}}=\frac{m I_{S}}{1-\alpha} \quad \text { with } \quad \Delta I_{\mathrm{FC}}=(2 \alpha-1) \frac{V_{\mathrm{FC}}}{L_{1} F} .
$$

The constraints on the semiconductor components are summarized in Table I.

Output characteristics are plotted in Fig. 5 in continuous conduction mode (CCM). For low-load conditions, a classical phenomenon of discontinuous conduction mode (DCM) occurs, which is similar to that obtained with the single-switch boost chopper. As a result, the output voltage depends on the current and increases for low output currents. At the same time, this phenomenon is amplified by the FC voltage increase. The output voltage $\left(V_{S}\right)$ can be expressed, in reduced coordinates, by

$$
y=1+\frac{\alpha^{2}}{2 x}
$$




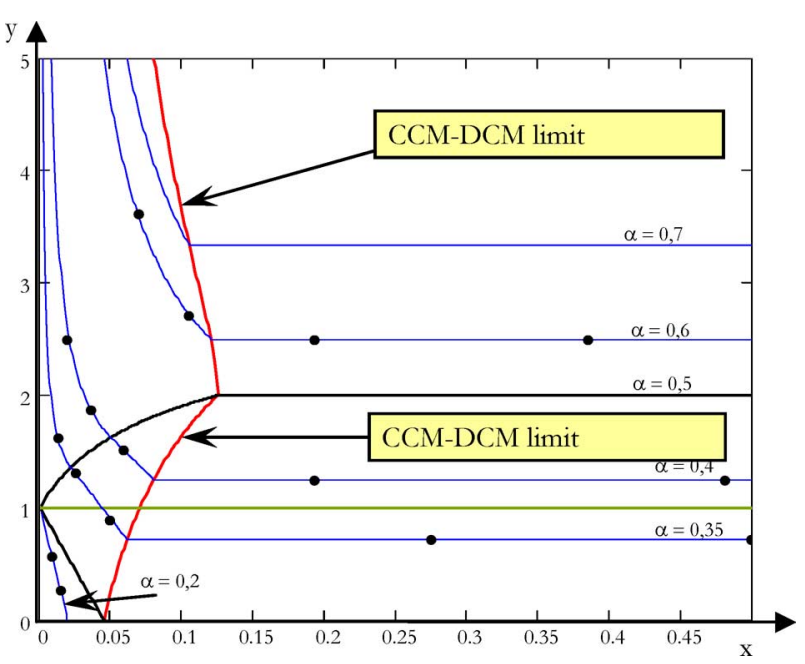

Fig. 5. Output characteristics.

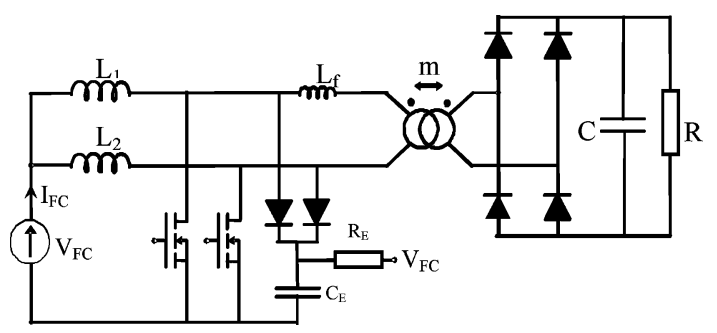

Fig. 6. RCD passive clamp.

where $x$ and $y$ represent the output current and output voltage, respectively

$$
\begin{aligned}
& x=\frac{m L_{f} I_{S}}{V_{\mathrm{FC}}} \\
& y=\frac{V_{S}}{m V_{\mathrm{FC}}} .
\end{aligned}
$$

The limit between CCM and DCM is plotted in Fig. 5; the black dots have been obtained by simulation and confirm the theoretical analysis.

Due to the leakage inductance of the transformer, a specific network, active or passive, is required to limit MOSFET overvoltage [4]. Two alternatives are proposed next: the first one dissipative and the second one using energy recovery.

\section{Two Variants of the Proposed Converter}

1) RCD passive clamp: The classical RCD network is used for both MOSFET where the resistance is connected to the input source in order to limit the dissipated power (Fig. 6). The main drawback concerns efficiency that is limited by the dissipated energy stored in the leakage inductor.

2) Nondissipative active clamp: A small buck converter is introduced between the capacitance clamp and the input source (Fig. 7). Thus, the voltage clamp can be controlled by the duty cycle of the additional step-down converter.

This solution provides better efficiency than the earlier topology, but indicates a slight increase in volume [5]. From a func-

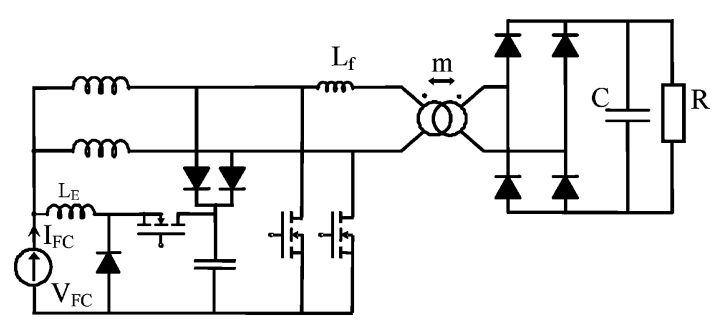

Fig. 7. Nondissipative active clamp.

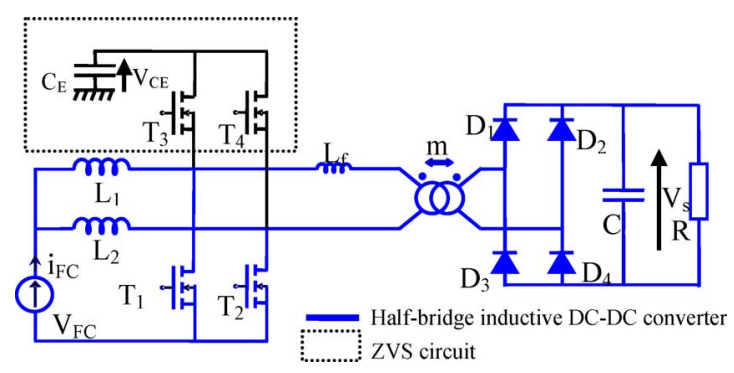

Fig. 8. ZVS half-bridge inductive dc-dc converter.

tional point of view, the operation for duty cycles less than 0.5 becomes possible due to energy recovery, as shown in Fig. 5.

\section{SOFT-SWITCHING DC-DC CONVERTERS: DESCRIPTION AND OPERATION ANALYSIS}

The half-bridge inductive dc-dc converter obtained from the interleaved boost converter indicates many interesting characteristics relative to the constraints imposed by the FC. However, the leakage inductor of the transformer remains the main drawback of this structure. The following two structures are proposed to deal with these weaknesses [6]-[8].

\section{A. ZVS Half-Bridge Inductive DC-DC Converter}

The ZVS structure, presented in Fig. 8, allows the operation with a duty cycle $\alpha$ less than 0.5 , and the leakage inductor is used to form the ZVS circuit [6]. Depending on the duty cycle (greater or less than 0.5) and the demagnetization current (total or partial), one of the following four behaviors can occur [9]:

Case 1: $\alpha>0.5$ and total demagnetization;

Case 2: $\alpha>0.5$ and partial demagnetization;

Case 3: $\alpha<0.5$ and total demagnetization;

Case 4: $\alpha<0.5$ and partial demagnetization.

We now describe these possible behaviors. In each case, we will consider only the first half period, the second one being identical.

1) Case 1: $\alpha>0.5$ and Total Demagnetization (Fig. 9):

Step 1: The voltage on the primary side of the transformer is initially $V_{\text {out }} / m$, and the current in the transformer is positive. This current decreases linearly to zero at $\beta T$

$$
L_{f} \frac{d I_{\mathrm{TR}}}{d t}=-\frac{V_{S}}{m} .
$$




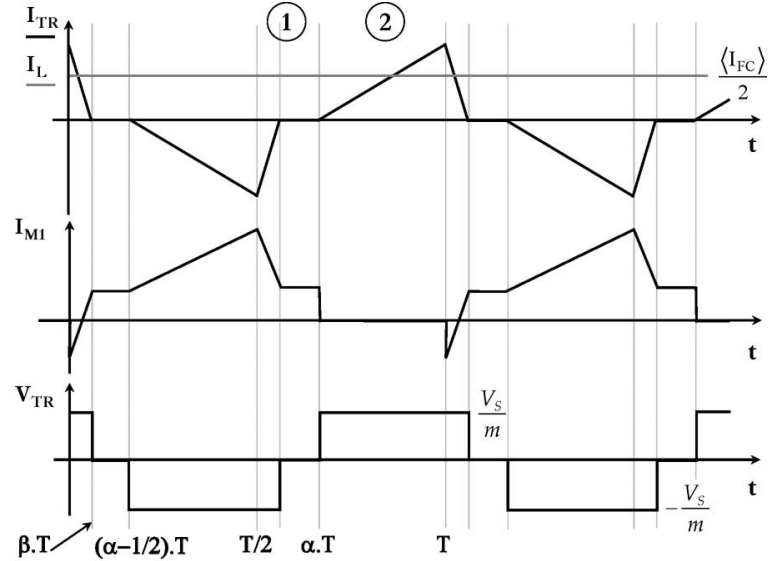

(1) $\frac{V_{S}}{m \cdot L_{f}}$ (2) $\frac{m \cdot V_{C}-V_{S}}{m \cdot L_{f}}$

Fig. 9. Case 1-main waveforms.

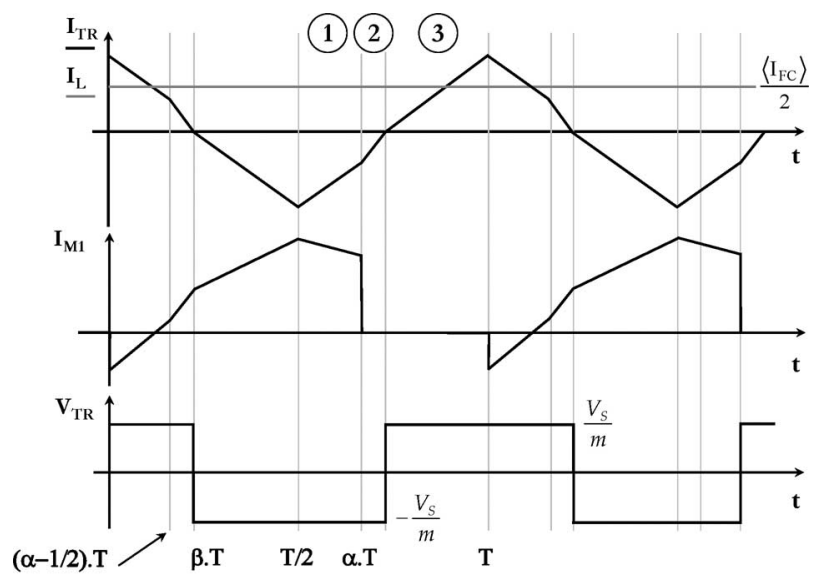
(1) $\frac{V_{S}}{m \cdot L_{f}}$
(2) $\frac{m \cdot V_{C}+V_{S}}{m \cdot L_{f}}$
(3) $\frac{m \cdot V_{C}-V_{S}}{m \cdot L_{f}}$

Fig. 10. Case 2-main waveforms.

Step 2: When this current reaches zero, diodes $D_{1}$ and $D_{4}$ do not conduct yet: the diode bridge is blocked. This phase ends with $T_{2}$ being switched off.

Step 3: Switch $T_{4}$ is on. The voltage on the primary side is imposed by $V_{\mathrm{CE}}$ of the capacitor. The current of the transformer becomes negative. The voltage and the current in the primary side of the transformer can be expressed by

$$
\begin{aligned}
L_{f} \frac{d i_{\mathrm{TR}}}{d t} & =-V_{\mathrm{CE}}+\frac{V_{S}}{m} \\
V_{\mathrm{TR}} & =-\frac{V_{S}}{m} .
\end{aligned}
$$

2) Case 2: $\alpha>0.5$ and Partial Demagnetization: In this case, the demagnetization of the transformer is partial (Fig. 10).

Step 1: This step happens identically as in case 1 . The current of the transformer $i_{\mathrm{TR}}$ decreases linearly and continuously but does not reach zero as in case 1 .

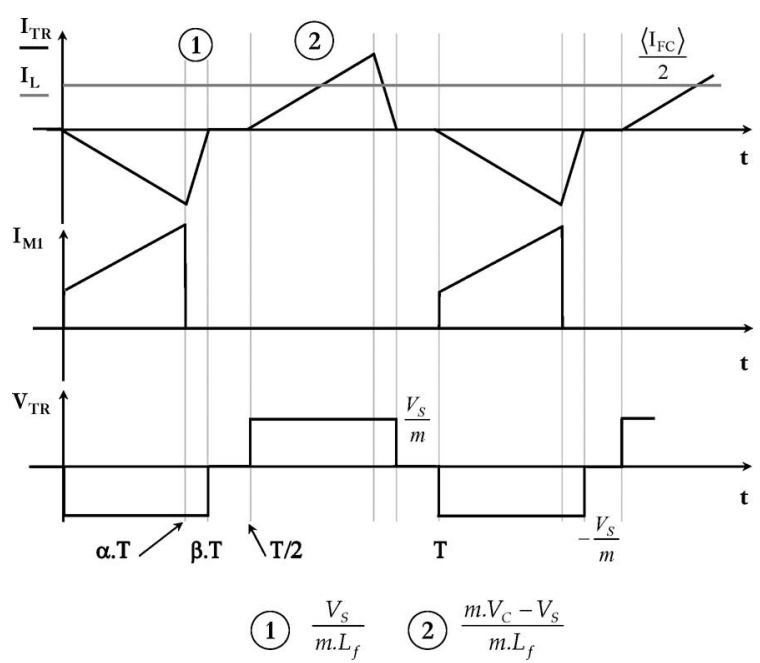

Fig. 11. Case 3-main waveforms.

Step 2: Switch $M_{2}$ is switched off, and $i_{\mathrm{TR}}$ is still positive and continues to decrease. The evolution of this current can be expressed by

$$
L_{f} \frac{d i_{\mathrm{TR}}}{d t}=-\left(V_{\mathrm{CE}}+\frac{V_{S}}{m}\right) .
$$

Step 3: $i_{\mathrm{TR}}$ changes sign. The conduction of $D_{2}$ and $D_{3}$ leads to the inversion of the transformer voltage. The evolution law of current and voltage during this step is identical to that in case 1 .

3) Case 3: $\alpha<0.5$ and Total Demagnetization (Fig. 11):

Step 1: The current in the transformer is initially zero. Switching $T_{1}$ on leads to the decrease of $i_{\mathrm{TR}}$. This current becomes negative

$$
L_{f} \frac{d i_{\mathrm{TR}}}{d t}=\frac{V_{S}-m V_{\mathrm{CE}}}{m}
$$

and

$$
V_{\mathrm{TR}}=-\frac{V_{S}}{m}
$$

Step 2: Switching $M_{1}$ off leads to switching $T_{3}$ on. The short circuit of TR and $L_{f}$ by the conduction of $T_{3}$ and $T_{4}$ leads to demagnetization of the transformer until the current reaches zero

$$
L_{f} \frac{d i_{\mathrm{TR}}}{d t}=\frac{V_{S}}{m} .
$$

4) Case 4: $\alpha<0.5$ and Partial Demagnetization (Fig. 12):

Step 1: $i_{\mathrm{TR}}$ is initially positive. It decreases when $M_{1}$ is switched on

$$
L_{f} \frac{d i_{\mathrm{TR}}}{d t}=-\frac{V_{S}+m V_{\mathrm{CE}}}{m} .
$$

Step 2: When demagnetization is complete, $i_{\mathrm{TR}}$ becomes negative, and diodes $D_{2}$ and $D_{3}$ conduct. The voltage of the transformer is reversed and the current can be expressed by

$$
L_{f} \frac{d i_{\mathrm{TR}}}{d t}=-V_{\mathrm{CE}}+\frac{V_{S}}{m} .
$$




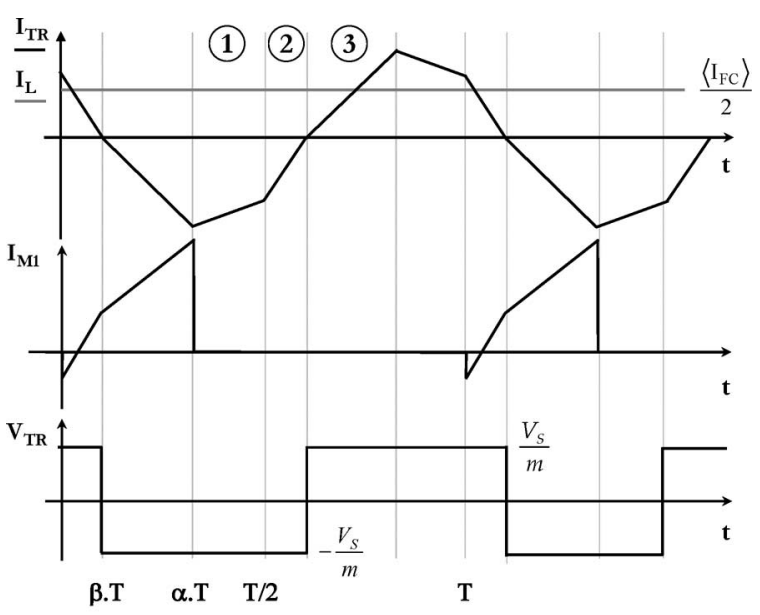

(1) $\frac{V_{S}}{m \cdot L_{f}}$ (2) $\frac{m \cdot V_{C}+V_{S}}{m \cdot L_{f}}$ (3) $\frac{m \cdot V_{C}-V_{S}}{m \cdot L_{f}}$

Fig. 12. Case 4-main waveforms.

TABLE II

OUTPUT CHARACTERISTICS

\begin{tabular}{|c|c|c|}
\hline & Output characteristics & Valid field \\
\hline $\begin{array}{l}\text { Case } \\
n^{\circ} 1\end{array}$ & $y=\frac{1}{x+(1-\alpha)}$ & $\begin{array}{c}y \geq 2 \\
\alpha \geq 1 / 2\end{array}$ \\
\hline $\begin{array}{l}\text { Case } \\
\mathrm{n}^{\circ} 2 \\
\end{array}$ & $y=2 \cdot \sqrt{\frac{2 \cdot x-\alpha}{\alpha-1}}$ & $\begin{array}{c}y \leq 2 \\
\alpha \geq 1 / 2\end{array}$ \\
\hline $\begin{array}{l}\text { Case } \\
n^{\circ} 3\end{array}$ & $y=\frac{\alpha}{(1-\alpha) \cdot(\alpha+(1-\alpha) \cdot x)}$ & $\begin{array}{c}y \geq 2 \cdot \alpha /(1-\alpha) \\
\alpha \leq 1 / 2\end{array}$ \\
\hline $\begin{array}{l}\text { Case } \\
\mathrm{n}^{\circ} 4\end{array}$ & $y=2 \cdot \sqrt{\frac{2 \cdot x-\alpha}{\alpha-1}}$ & $\begin{array}{c}y \leq 2 \cdot \alpha /(1-\alpha) \\
\alpha \leq 1 / 2\end{array}$ \\
\hline
\end{tabular}

Output characteristics: To analyze the output characteristics, we use variables $x$ and $y$ defined as

$$
\begin{aligned}
& y=\frac{V_{S}}{m V_{\mathrm{FC}}} \\
& x=\frac{m L_{f} f I_{S}}{V_{\mathrm{FC}}} .
\end{aligned}
$$

The characteristics corresponding to different cases are presented in Table II and Fig. 13.

\section{B. ZCS Half-Bridge Inductive Converter}

The ZCS structure (Fig. 14) is obtained from the interleaved boost converter by introducing a transformer and a diode bridge at its output [10]. The leakage inductor of the transformer is used to create the resonance circuit while the capacitor is placed on the secondary side of the transformer. However, for the analysis of the operation, this capacitor is considered as being on the primary side. In addition, the leakage inductor also plays an additional role as that of a soft-switching circuit. On the secondary side, the diode bridge rectifier exhibits low losses due to the weaker current. A drawback of this topology is that the duty cycle must be greater than 0.5 . Nevertheless, this is not the case for project specification because of the low input voltage of FC and the requirement of high output voltage.

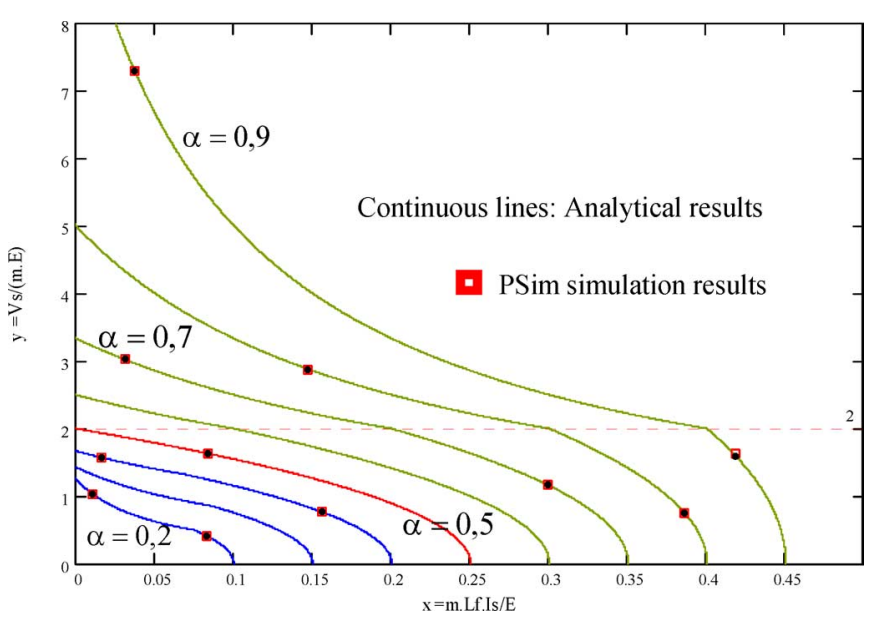

Fig. 13. Output characteristics.

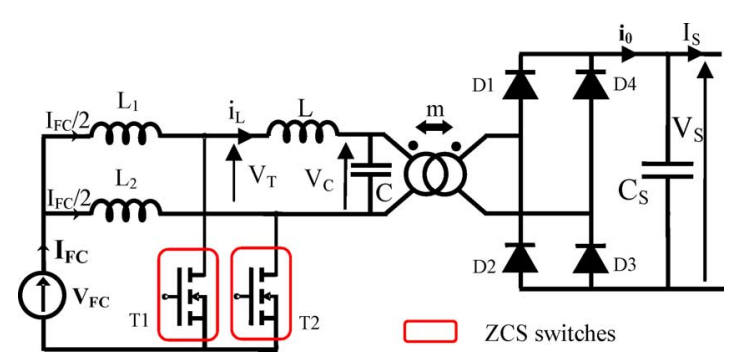

Fig. 14. ZCS half-bridge inductive dc-dc. converter.

One complete switching cycle can be divided into four steps. Each step is briefly described as follows.

1) Initial Condition: The circuit is in steady state. $T_{1}, D_{1}$, and $D_{3}$ are conducting. So

$$
i_{L}=I=\frac{I_{\mathrm{FC}}}{2} \quad V_{C}=\frac{V_{S}}{m} .
$$

Step 1: $t \in\left[0, t_{1}\right], T_{2}$ is switched on at 0

$$
V_{L}=L \frac{d i_{L}}{d t}=-\frac{V_{S}}{m} \Rightarrow i_{L}=-\frac{V_{S}}{m L} t+I .
$$

This phase finishes when $i_{L}=0$ and the diodes on the secondary side are switched off

$$
t_{1}=\frac{I_{\mathrm{FC}}}{2} \frac{m L}{V_{S}} .
$$

Step 2: $t \in\left[t_{1}, t_{2}\right]$ : beginning of the resonance

$$
\left\{\begin{array}{l}
V_{C}=\frac{V_{S}}{m} \cos \left(\omega_{r} t\right) \\
i_{L}=-\frac{V_{S}}{m Z} \sin \left(\omega_{r} t\right)
\end{array}\right.
$$

with

$$
Z=\sqrt{\frac{L}{C}} \quad T_{r}=2 \pi \sqrt{L C}
$$

Switch $T_{1}$ is turned off if $i_{T_{1}}=0=I+i_{L} \Leftrightarrow i_{L}=$ $-I$. So

$$
t_{2}=t_{1}+\frac{1}{\omega_{r}}\left[\pi-\arcsin \left(\frac{I_{\mathrm{FC}} m Z}{2 V_{S}}\right)\right] .
$$




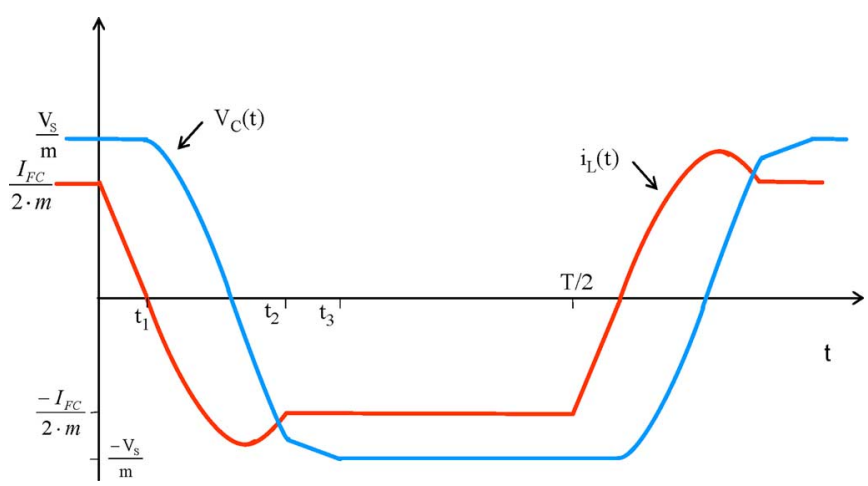

Fig. 15. Waveforms in resonant circuit $(L-C)$.

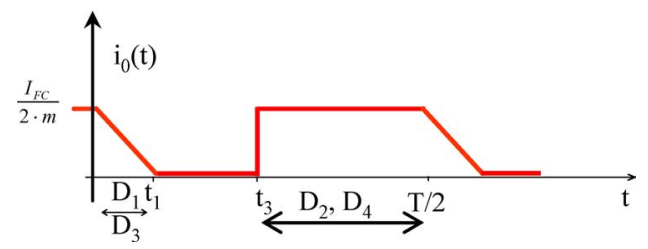

Fig. 16. Output current.

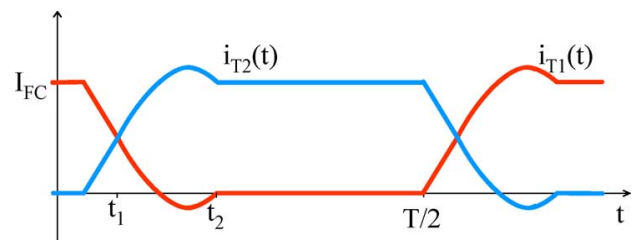

Fig. 17. Switches currents.

Step 3: $t \in\left[t_{2}, t_{3}\right]: T_{1}$ is turned off.

The capacitor discharges with a constant current

$$
V_{C}=V_{C}\left(t_{2}\right)-\frac{I}{C} t
$$

When $V_{C}=-V_{S} / m$, diodes $D_{2}$ and $D_{4}$ begin to conduct

$t_{3}=t_{2}+\frac{2 C}{I_{e}}\left[\frac{V_{S}}{m}\left(1+\cos \left(\pi-\arcsin \left(\frac{I_{\mathrm{FC}} m Z}{2 V_{S}}\right)\right)\right)\right]$.

Step 4: $t \in\left[t_{3}, T / 2\right]$ : steady state established.

Primary voltage and output current are calculated by

$$
V_{c}=\frac{-V_{S}}{m} \quad \text { and } \quad I_{S}=\frac{-I}{m} .
$$

At $t=T / 2, T_{1}$ is turned on: it is the start of an opposite cycle.

2) Voltage and Current Waveforms: The main current and voltage waveforms are presented in Figs. 15-18. An interesting feature to be noted is that the overcurrent during the commutation is limited to a value near the current in the switched mode. This current is much lower than the overcurrent in a classical resonance-switch converter.

3) Output Characteristics: Note that $T_{r}=2 \pi \sqrt{L C}$ and $T_{0}=t_{3}-t_{1}$.

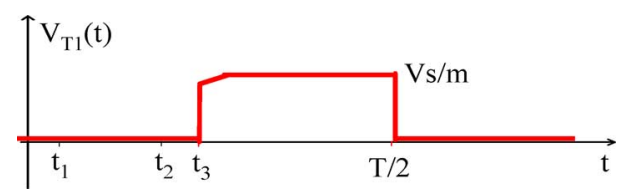

Fig. 18. Switch voltage.

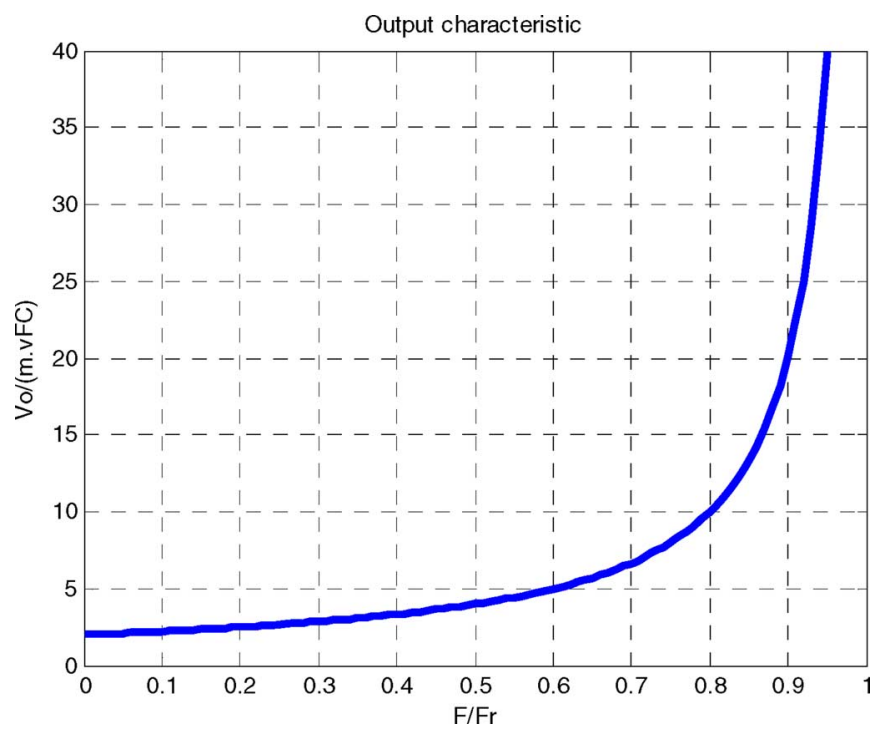

Fig. 19. Output voltage versus switching frequency.

The average output current can be calculated approximately

$I_{S}=2 \frac{I_{\mathrm{FC}}}{2 m} \frac{(T / 2)-T_{0}}{T}=\frac{I_{\mathrm{FC}}}{2 m}\left(1-\frac{2 T_{0}}{T}\right)=\frac{I_{\mathrm{FC}}}{2 m}\left(1-\frac{f}{f_{r}}\right)$.

As for voltage, by applying power conservation

$$
\begin{aligned}
V_{\mathrm{S}} \cdot I_{\mathrm{S}} & =V_{\mathrm{FC}} \cdot I_{\mathrm{FC}}=>\frac{V_{S}}{m V_{\mathrm{FC}}}=\frac{2}{1-\left(f / f_{r}\right)} \\
\text { with } \quad f_{r} & =\frac{1}{2 \pi \sqrt{L C}} .
\end{aligned}
$$

The output voltage characteristic is illustrated in Fig. 19. This figure is reminiscent of the output characteristic of the hard-switching converter, by replacing the duty cycle by the ratio $f / f_{r}$. Thus, the output voltage can be controlled by only adjusting the ratio between the switching frequency $f$ and the resonance frequency $f_{r}$. In addition, as the switching frequency is variable, it might create the risk of parasite resonance due to $L$ and $C_{\text {oss }}$ from the MOSFET.

4) Essential Relations and Constraints (Table III): As the leakage inductor is used as a resonance inductor, the resonance capacitor must be placed on the secondary side.

\section{EXPERIMENTAL RESULTS}

Two converters were built corresponding to the two structures presented so as to validate the earlier analysis. 
TABLE III

SEMICONDUCTORS AND CAPACITOR CONSTRAINTS

\begin{tabular}{|c|c|}
\hline $\mathrm{T}_{1}$ and $\mathrm{T}_{2}$ & Output diodes \\
\hline $\mathrm{V}_{\mathrm{T} \max }=\frac{\mathrm{V}_{\mathrm{S}}}{\mathrm{m}}$ & $\mathrm{V}_{\mathrm{D} \max }=\mathrm{V}_{\mathrm{S}}$ \\
\hline $\mathrm{i}_{\mathrm{T} \max }=\frac{\mathrm{I}_{\mathrm{FC}}}{2}+\frac{\mathrm{V}_{\mathrm{S}}}{\mathrm{m} \cdot \mathrm{Z}}$ & $\mathrm{i}_{\mathrm{D} \max }=\frac{\mathrm{I}_{\mathrm{FC}}}{2 \cdot \mathrm{m}}$ \\
\hline \multicolumn{2}{|c|}{$\mathrm{V}_{\mathrm{C}, \mathrm{RMS}}=\mathrm{V}_{\mathrm{S}}$ (on secondary side) } \\
\hline
\end{tabular}

TABLE IV

REFERENCES AND CHARACTERISTICS OF MAIN COMPONENTS

\begin{tabular}{|l|l|}
\hline MOSFETs & International Rectifier IRFP90N20D \\
\hline Diodes & International Rectifier 30EPH06 \\
\hline Capacitors & BC Components 470 $\mu \mathrm{F}-400 \mathrm{~V}$ \\
\hline Inductors & $\begin{array}{l}\text { Magnetics 58439A2, High Flux } \mu=60,45 \\
\text { turns AWG\#13 }\end{array}$ \\
\hline Transformer & $\begin{array}{l}\text { Philips Core ETD59-ferrite 3F3, } \mathrm{m}=2.8 \\
\end{array}$ \\
$\begin{array}{l}\text { Primary: 13 turns, } 4 * 160-0.1 \mathrm{Litz} \text {-wire } \\
\text { Secondary: 33 turns, } 1 * 160-0.1 \text { Litz-wire } \\
\text { Measured leakage inductance }=800 \mathrm{nH}\end{array}$ \\
\hline
\end{tabular}

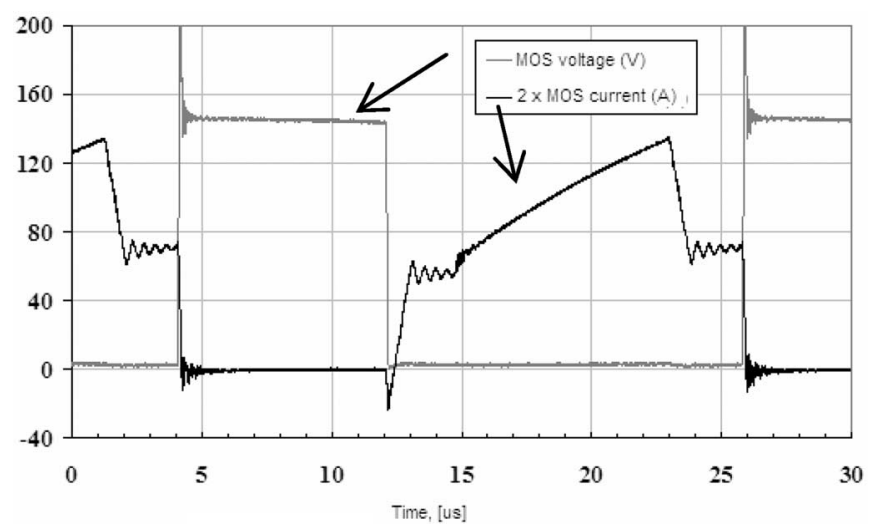

Fig. 20. MOSFET current and voltage $(P=2 \mathrm{~kW}, \alpha>0.5)$.

\section{A. ZVS Half-Bridge Inductive Converter}

A 2-kW prototype is designed according to Table I. The output voltage is controlled to $370 \mathrm{~V}$ and switching frequency is $50 \mathrm{kHz}$.

References and characteristics of the main components are listed in Table IV.

The main waveforms are shown in Figs. 20 and 21; efficiency at nominal load is $95.8 \%$.

\section{B. ZCS Half-Bridge Inductive Converter}

A 2-kW prototype of ZCS converter has been built. The output voltage is controlled at $350 \mathrm{~V}$. Main characteristics of passive components are given in Table $\mathrm{V}$.

An overvoltage of about $50 \mathrm{~V}$ can be noticed during turnoff time. This phenomenon is due to capacitor $C_{\mathrm{OSS}}$ of the MOSFET and the resonance inductor. Consequently, a clampedvoltage $R C D$ circuit is introduced. Fig. 22 shows the effect of this clamp on voltage $v_{T}$ that is primary transformer voltage when resonant capacitor is placed on the secondary side of the transformer. The overcurrent can also be explained by the recov-

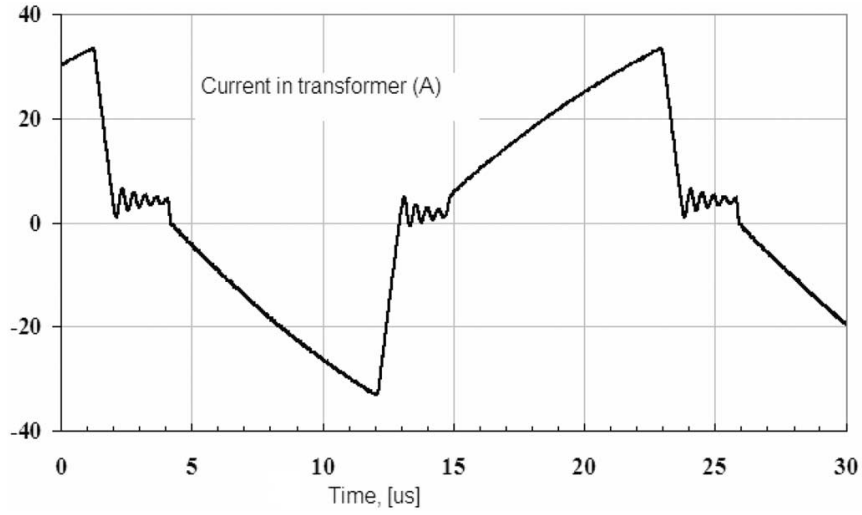

Fig. 21. Current in primary side of transformer $(P=2 \mathrm{~kW}, \alpha>0.5)$.

TABLE V

MaIN CHARACTERISTICS OF PASSIVE COMPONENTS

\begin{tabular}{|l|l|}
\hline $\begin{array}{l}\text { Resonant } \\
\text { capacitor }\end{array}$ & Eurofarad RA 14 \\
\hline $\begin{array}{l}\text { Input } \\
\text { inductors }\end{array}$ & $\begin{array}{l}\text { Magnetics 58439A2, High Flux } \mu=60,17 \\
\text { turns AWG\#13 }\end{array}$ \\
\hline Transformer & $\begin{array}{l}\text { Philips Core ETD59-ferrite 3F3, m }=2.3 \\
\text { Primary: 13 turns, } 6 * 50-0.1 \text { Litz-wire } \\
\end{array}$ \\
& $\begin{array}{l}\text { Secondary: 33 turns, } 2 * 250-0.1 \text { Litz-wire } \\
\text { Measured leakage inductance }=500 \mathrm{nH} .\end{array}$ \\
\hline
\end{tabular}

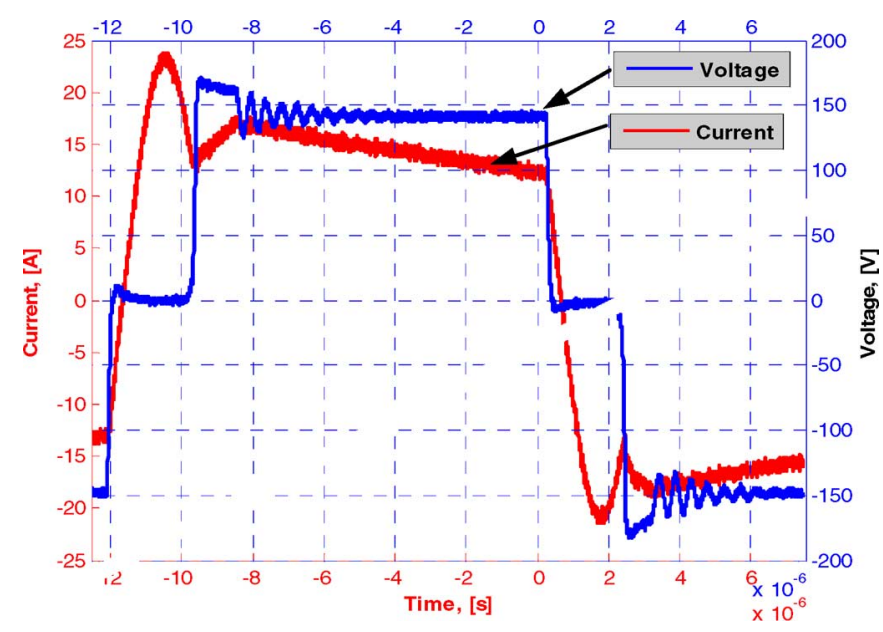

Fig. 22. Current in resonant inductor and voltage $v_{T} \cdot P_{\text {out }}=2 \mathrm{~kW}$.

ery phenomenon of the MOSFET diode. This can be reduced by using MOSFETs with better body diode. The measured efficiency is $96 \%$.

\section{CONCLUSION}

In this paper, after a review of well-suited dc-dc converter for FC applications, we have developed two soft-switching $\mathrm{dc}-\mathrm{dc}$ converters based on the half-bridge inductive converter. The ZVS converter overcomes the duty cycle limit of the original structure and avoids the effects from the leakage inductor by using it in the resonance circuit. The ZCS converter uses 


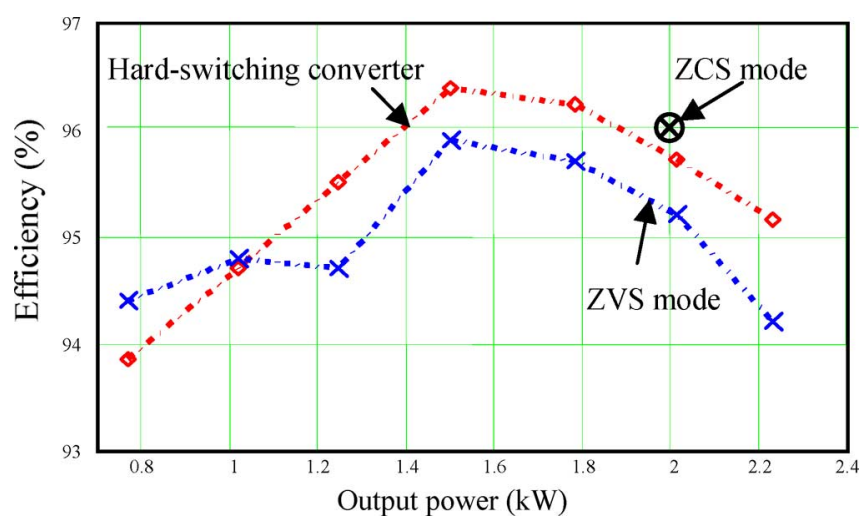

Fig. 23. Compared efficiency of the three converters. Output power (in kilowatts).

the transformer leakage inductor to create the resonance circuit, but still cannot operate at duty cycle below 0.5 . However, it is suitable for FC applications because its output voltage is relatively high in comparison with the FC voltage. Moreover, the structure is simple and uses less components. Low losses are incurred in the semiconductors because the controlled semiconductors (MOSFET) are used only on the primary side (low voltage side) and diodes are used on the high voltage side. Soft switching reduces switching losses. A high ratio between output and FC voltages is obtained while ensuring a high efficiency: modularity is thus possible. The efficiency was compared between the three structures at nominal power (Fig. 23). First, the efficiency in ZVS mode remains lower than that of the basic structure because of the conduction losses. In addition, ZCS mode exhibits a slightly better efficiency at full power.

\section{REFERENCES}

[1] J. Wang, P. Z. Peng, J. Anderson, A. Joseph, and R. Buffenbarger, "Low cost fuel cell converter system for residential power generation," IEEE Trans. Power Electron., vol. 19, no. 5, pp. 1315-1322, Sep. 2004.

[2] H. Xu, L. Kong, and X. Wen, "Fuel cell power system and high power DC-DC converter," IEEE Trans. Power Electron., vol. 19, no. 5, pp. 12501255, Sep. 2004.

[3] G. Lefèvre, J. Barbaroux, J.-P. Ferrieux, and P. Boggetto, "A new DC-AC converter for portable fuel cell applications," presented at the EPE Conf. 2003, Toulouse, France, Sep.

[4] S.-J. Jang, C.-Y. Won, B.-K. Lee, and J. Hur, "Fuel cell generation system with a new active clamping current-fed half-bridge converter," IEEE Trans. Energy Convers., vol. 22, no. 2, pp. 332-340, Jun. 2007.

[5] G. Lefèvre, J.-P. Ferrieux, J. Barbaroux, P. Boggetto, and P. Charlat, "Minimizing magnetic components losses in a new DC-DC converter for portable fuel cell applications," in Conf. Rec. IEEE-IAS, Seattle, WA, Oct. 2004, pp. 1273-1279.

[6] G.-J. Su, F. Z. Peng, and D. J. Adams, "Experimental evaluation of soft switching DC-DC converter for fuel cell vehicle applications," in Proc. IEEE Workshop Power Electron. Transp., 2002, pp. 39-44.

[7] H. Li, F. Z. Peng, and J. S. Lawler, "A natural ZVS medium power bidirectional DC-DC converter with minimum number of devices," IEEE Trans. Ind. Appl., vol. 39, no. 2, pp. 525-535, Mar./Apr. 2003.
[8] F. Z. Peng, H. Li, G.-J. Su, and J. S. Lawler, "A new ZVS bidirectional DC-DC converter for fuel cell and battery application," IEEE Trans. Power Electron., vol. 19, no. 1, pp. 54-65, Jan. 2004.

[9] G. Lefèvre, "Conception de convertisseurs statiques pour I'utilisation de la pile à combustible," Ph.D. dissertation, Lab. Electrotech. Grenoble, Inst. Nat. Polytech. Grenoble (INPG-LEG), Grenoble, France, 2004.

[10] A. Ivanes, V. D. Bang, Y. Lembeye, J. P. Ferrieux, and J. Barbaroux, "Comparison of two soft switching DC-DC converters for fuel cell applications," in Conf. Rec. IEEE IAS, Oct. 2006, pp. 2121-2128.

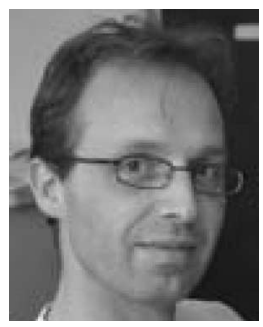

Yves Lembeye received the Ph.D. degree in electrical engineering from Grenoble Institute of Technology, Grenoble, France, in 1997.

$\mathrm{He}$ is currently an Associate Professor at the Institut Universitaire de Technologie 1 de Grenoble, Université Joseph Fourier, Grenoble, where he is involved in research activities at Grenoble Electrical Engineering Laboratory (G2Elab). His current research interests include low-power $\mathrm{dc}-\mathrm{dc}$ and ac-dc converters, high-current low-voltage converters, and passive components integration.

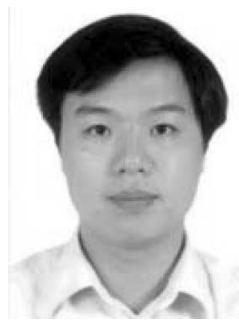

Viet Dang Bang received the B.Eng. degree in electrical engineering from Hanoi University of Technology, Hanoi, Vietnam, in 2002, the M.Eng. degree from Grenoble Institute of Technology, Grenoble, France, in 2003, and the Ph.D. degree from Joseph Fourier University, Grenoble, in 2006.

From 2007 to 2008, he was a Research Associate at the Power Conversion Group, School of Electrical and Electronic Engineering, University of Manchester, Manchester, U.K. He is currently with Vietnam Electricity, Hanoi, Vietnam. His current research interests include power converter design for renewable energy applications and applications of power electronics in power systems.

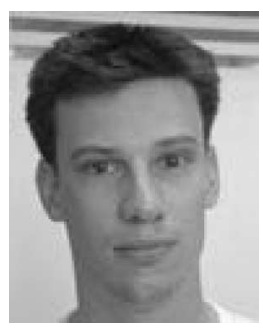

Guillaume Lefèvre received the Graduate degree in electrical engineering from Grenoble Institute of Technology, Grenoble, France, in 2001, and the Ph.D. degree from Joseph Fourier University, Grenoble, in 2004.

He is currently with CEFEM Technologies, Saint Michel de Boulogne, France. His current research interests include power electronics and magnetic devices.

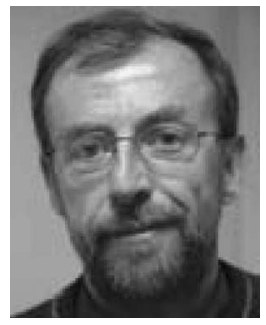

Jean-Paul Ferrieux received the Ph.D. degree and the HDR in electrical engineering from Grenoble Institute of Technology, Grenoble, France, in 1984 and 1989, respectively.

$\mathrm{He}$ is currently a Professor at the Institut Universitaire de Technologie, Université Joseph Fourier, Grenoble, where he is with Grenoble Electrical Engineering Laboratory (G2Elab). His current research interests include power electronics (static and resonant converter integration). He has authored or coauthored over 80 technical papers, and has coauthored a book on power electronics entitled Switch-Mode Power Supplies, Resonant Converters. 